Einen weitern wichtigen Umstand bei der Arsenikvergiftung bietet nach Novati das Blut dar. Es erscheint flüssig und sehr schwarz, wie bei Choleraleichen. Ein solcher Umstand erfordert Aufmerksamkeit und kann schon eine Arsenikvergiftung vermuthen lassen. Die Doctoren $\mathrm{Capsoni}$ und $\mathrm{C}$ a so rat $\mathrm{i}$ fafsten hieraus $\mathrm{Ver}$ dacht, bei der Section des Leichnams eines gewissen Catassi, und die geforderte gerichtliche Untersuchung bestätigte solchen. Durch Versuche an Thieren hat dieser Character als constant sich herausgestellt, das Arsenik mochte durch den Mund oder endermisch beigebracht sein; das Blut besafs stets eine schwarze Purpurfarbe, färbte Leinwand rothbraun, wie Kermes, war flüssig, zähe, opals und coagulirte nicht. Auch bei drei Leichen, die Novati untersuchte, fand es sich so. Man darf bei dieser Sache aber auch erwägen : 1) daโs das Blut in mehren Krankheiten einen ähnlichen Character zeigen kann; 2) dafs andere Gifte vielleicht ähnliche Resultate geben können; 3) dars, wenn der Tod nicht nnmittelbar erfolgt, die entzündliche Reaction die Charactere des Bluts ganı verändern kann. Glücklicherweise sind diese übrigens nicht die einzigen, nm eine Vergiftung zu erkennen. (Journ. de Chim. med. 2. Ser. V, 128.)

\title{
Ueber die Auffindung des Arseniks bei Vergiftungsvorfällen;
}

von

Orfila.

Eine nene grofse Arbeit ist von Orfila unternommen worden, um den Arsenik bei Vergiftungsfallen zu 
entdecken, und ihn aus allen Organen darzustellen, die das Gift absorbirt haben möchten (Vergl. Journ. de Chim. med. 2. Ser. $V, 516)$. Statt der Verbrennung der organischen Substanzen durch Salpeter u. s. w., hält er es für zweckmärsig, dieselben durch Erhitzen mit concentr. Salpetersäure zu zerstören, wobei aber ein gewisses bestimmtes Verhältnifs der Säure $z u$ beachten ist, weil sonst ein Erglühen und Entflammen der Masse statt fndet, wodurch ein Theil des Arseniks verloren geht, wenn nicht aller.

Das Verfahren, welches bei Behandlung solcher Organe zu befolgen ist, giebt $O r$ fil a folgendermaafsen an.

Man lärst die zerschnittenen Eingeweide sechs Stunden lang mit dest. Wasser, dem man 2-3 Gran durch Alkohol gereinigtes Kali zugesetzt hat, in einer Porcellanschale auskochen, das Decoct filtriren, mit Chlorwasserstoffsäure übersättigen und durch Schwefelwasserstoff faillen.

W'enn man Gliedmalsen der Auskochung unterworfen hat, so mufs man das Decoct vor dem Behandeln mit Schwefelwasserstoff erkalten lassen, damit das Fett sich absondere, weil sonst die nachherige Verbrennung der übrigen Bestandtheile durch Salpetersäure zu lebhaft sein und man dadurch einen Verlust an Arsenik haben würde. Es trifft sich, dafs die Auflösung nach einigen Tagen einen Niederschlag von Schwefelarsenik und animalischer Materie absetzt, oder der Niederschlag blors aus letzter besteht. Die über dem Niederschlage befindliche Flüssigkeit wird filtrirt, zur Trockne verdunstet, und der Rückstand mit Salpetersäure behandelt, um den Arsenik noch zu erhalten, welcher durch Schwefelwasserstoff nicht gefällt wurde. 
Die mit Wasser ausgekochten Eingeweide werden dann in märsiger Wärme yetrucknet und gewogen, um danach die Menge Salpetersäure zu bestimmen, die zu deren Zerstürung nüthig ist. Im Allgemeinen gaben zwar die durch kochendes Wasser erschüpften Organe keinen Gehalt von Arsenik mehr zu erkennen, doch ist es demohnerachtet nothwendiy, sie noch mit Salpetersäure zu behandeln, weil sie durch nuch nicht erklärte Ursachen immer noch etwas Arsenik zurückhalten können. Immer ist aber das vorherige Auskochen mit Wasser $z u$ rathen, weil die Salpetersïure auf ein Organ, welches Arsenik enthält, nicht wirken kann, ohne einen merklichen Verlust des Giftes herbeizuführen; durch das vorherige Auskochen mit Wasser und rällen des Decocts mit Schwefelarsenik, mufs der unvermeidliche Verlust jedentalls auf eine kleine Quantität des Giftes. beschränkt werden.

Folgendes sind die Verhältnisse der Salpetersäure von $41^{\circ}$ zu den verschiedenen getrockneten Substanzen, die $0 \mathrm{rfila}$ am geeignetsten findet:

3 Unzen trocknes Blut: 7 Unzen Säure.

3 Unzen trocknes Product eines entfetteten Decocts von Gliedmarsen : 9 Unzen Säure.

Das grofse und kleine Gehirn eines Erwachsenen, trocken 6 Unzen wiegend : $2 \frac{1}{4}$ Pfd. Säure.

Die beiden Lungen, getrocknet 5 Unz. : 1 Pfd. Säure.

Das Herz, getrocknet 1 Unze 6 Drachmen: 5 Unz. Säure.

Die trockne Leber, 12 Unzen: 3 Pfd. Säure.

Die trockne Milz, 1 Unze 2 Drachmen: $3 \frac{1}{2}$ Unzen Säure.

3 Unzen trockner Substanz des Magens und des Darmkanals : 9 Unzen Säure. 
Die beiden getrockneten Nieren, 2 Unzen : 6 Unzen Sänre.

22 Unzen trocknes Muskelfleisch : $4 \frac{1}{4}$ Pfd. Säure.

Das Verfahren bei der Belandlung mit Salpetersäure ist nach Orfila dieses: Die ganze Menge der Säure wird in einer Porcellanschale über mälsigem Feuer erhitzt, und in $\mathbf{Z}$ wischenräumen von ungefähr $I$ Minute werden Stückchen der organischen Materie hineingeworfen; es entwickelt sich sogleich Stickstoffoxydgas, die Flüssigkeit kömmt ins Kochen, und die Substanz löst sich auf. Würde man die organische Substanz auf einmal hineinbringen, so würde ein Aufschäumen und Uebersteigen eintreten. Die saure Flüssigkeit färbt sich nach und nach dunkelroth, wird dick und fängt am Rando an sich zu verkohlen, man wartet non noch, bis die Verkohlung so weit vorgeschritten ist, dafs aus der Schale so dicke weifse Dämpfe aufsteigen, dafs man kaum in selbige hineinsehen kann. Man nimmt dio Schale vom Feuer, läfst sie erkalten, die Koble in einem Porcellan-oder Glasmörser pülvern und 25 Minuten lang mit 7-8 Unzen Wasser auskochen, um die durch Einwirkung der Salpetersäure auf die Arsenichtsäure entstandene Arsenilssäure aufzulösen und bringt die filtrirte Auflösung in einen zuvor geprüften Matsh'schen Apparat, der mit arsenikfreiem Zink und reiner Schwefelsäure versehen ist. Sollte nun ein starkes Aufschäumen erfolgen, so giefst man die Flüssigkeit schnell in einen grofsen Trichter, den man unten mit einem Finger verschliefst. Ein grofser Theil des Schaums bleibt in dem Apparat hängen, den man mehrmals auswäscht, während dieser Zeit hat die Flüssigkeit im Trichter sich in zwei Theile geschieden, in eine obere schanmige und eine untere flüssige; diese letztere läfst man nun in den ApArch. d. Pharm. II. Reihe. XXIII. Bds. 1. Hft. 
parat laufen. Nach einigen Minuten entwickelt sich langsam Arsenikwasserstoffgas, und in dem Maafse, wie dieses verbrennt, setzt es auf einer Porcellanplatte die Arsenikflecken ab. Bei Beachtung dieser Vorsichtsmaarsregel bildet sich selten aufs Nene wieder Schaum, so dafs man nicht nöthig hat, Olivenöl zuzusetzen; sollte dieses dennoch erforderlich sein, so bringt man 2 Unzen Oel in den Apparat, und der Versuch geht dann ohne Schwierigkeit fort; verlangsamt sich die Gasentwicklung nach und nach, so murs man etwas Schwefelsäure zusetzen, selbst damit das Gas mit einer schwachen Flamme brenne.

Nachdem man auf diese Weise den gröfsten Theil des Arseniks abgeschieden hat, wird die ausgekochte Kohle mit $\frac{1}{2}$, 1 oder 2 Unzen krystallisirten Salpeter vermischt und das Gemenge in einem hessischen Tiegel verbrannt; die Asche zersetzt man mit reiner concentrirten Schwefelsäure, bis sich kein Salpetergas mehr entwickelt.

Die abfiltrirte Flüssigkeit kann in dem Marsh'schen Apparat noch eine kleine Menge Arsenik ergeben, wenn ein Theil der in der Kohle enthaltenen Arseniksäure den kohlensauren Kalk der Kohle in arseniksauren Kalk umgeändert hätte, der in Wasser unlöslich ist.

Wenn man die verdächtige organische Materie vor der Behandlnng mit Salpetersäure nicht gehörig austrocknet, und sie noch feucht ist, so entsteht nachher bei der Einwirkung dieser Säure ein heftiges Anfschäumen, selbst ein Uebersteigen, and man kann dadurch Verluste exleiden.

Jedenfalls ist noch zu erinnern, dafs wenn man mehr Salpetersänre anwendet, als die Vorschrift besagt, die Temperatur höher ist, und da Schälchen während der Verkohlung auf dem Fener bleibt: die Zersetzang dann 
oft mit Entflammung vor sich geht, besonders bei Behandlung fetter Materien, und dars dadurch der Arsenik gänzlich oder gröfstentheils sich verflüchtigen kann.

Von den mannichfachen Versuchen, die Orfil a nach diesem Verfahren angestellt hat, wollen wir nur einige anführen.

Ein Hund war mit 12 Gran in 4 Unzen Wasser aufgelöster Arsenichtsäure vergiftet, die in den Magen eingebracht warde. Das Blut, das Herz, die Lungen, dio Leber, die Milz, die Nieren, und das getrocknete Product der Auskochung der Gliedmaafsen des vergifteten Hundes wurden, jeder Theil für sich, mit Salpetersäure behandelt. Die Kohle dieser zersetzten organischen Materien gab, mit Wasser gekocht und die Auskochung in dem Marsh'schen Apparat geprüft, bemerkliche Mengen von Arsenik zu erkennen.

Die Flüssigkeit, welche man durch Auskochen des Magens eines gewissen an Gift gestorbenen So u f flard's mit Wasser, dem etwas Salzsäure zugesetzt worden war, erhalten hatte, wurde mit Schwefelwasserstoff gefällt. Nach drei Monaten hatte sich viel Schwefelarsenik darin abgesetzt. Die davon abfiltrirte Flüssigkeit roch noch nach Schwefelwasserstoff; sie wurde verdunstet und der Rückstand durch Salpetersäure verkohlt, worauf die Kohle mit Wasser ausgekocht wurde. Die Flüssigkeit ergab bei ihrer Prüfung im Marsh'schen Apparat eine ziemliche Zahl von Arsenikflecken. Diese Erfahrung bestätigt die frühere, da「s Schwefelwasserstoff aus Flüssigkeiten, die organische Materien aufgelöst enthalten, nicht allen Arsenik ausfällt.

Die Leber aus dem Leichname eines gewissen $\mathrm{Ni}$ col as Mercie r, von dem man Verdacht schöpfte, dafs er an Vergiftung gestorben sei, und schon seit fünf Monaten 
beerdigt war, gab durch Verkohlen mit Salpetersäure, Auskochen der Kohle mit Wasser und Behandeln der Flüssigkeit im Marsh'schen Apparate, eine bedeutendo Menge von Arsenikflecken.

Eine Madame $M$. hatte einen Theelöffel voll Arsenichtsäure eingenommen, um sich zu vergiften. Als dio eingetretenen Zufälle nach zwölf Stunden einen Aderlafs nothwendig machten, wurde eine Vene geöffnet.

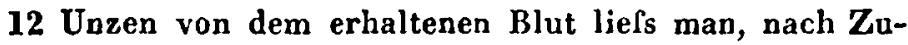
satz von 4 Gran reinem kaustischen Kali, eintrocknen, und das Product, $2 \frac{1}{2}$ Unze, durch 5 Unzen Salpetersäure von $41^{\circ}$ eintrocknen. Die Verkohlung ging rasch und ohne Entzündung vor sich. Die voluminöse und trockne Kohle gab darch Auslsochen mit Wasser eine röthliche wenig sauer reagirende Flüssigkeit, die bei ihrer Prüfung im Marsh'schen Apparate einige zwanzig wenig gefärbte aber glänzende Arsenikflecken ergab. Das Wichtigste bei diesem Verfahren ist, wie man sieht, die Zerstörung der organischen Substanz durch die Salpetersäure. Die nachherige Auskochung der erhaltenen Kohle kann man dann dem Versuch in dem Apparat von Ma r sh unterwerfen, oder auch durch Schwefelwasserstotf fällen and das erhaltene Schwefelarsenik reduciren.

\section{Wirksamkeit des Eisenoxydhydrats gegen Arsenikvergiftung.}

Hr. Dr. Lüdicke in Breslau berichtet folgenden Fall. Ein Weinhändler trank am 4. Sept. 1837 Mittags von einem Fliegenwasser, das aus Unvorsichtigkeit zwischen Weinflaschen gerathen war, und das er für einen 